\title{
Controls over solitary confinement needed
}

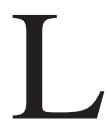

egal cases condemning misuse of solitary confinement in Canada's federal and provincial jails are propelling calls for external independent controls over the practice.

"The time is long overdue for a prohibition on segregation of inmates who are suicidal, who are self-harming, or who have significant mental illnesses," says Howard Sapers, Canada's correctional investigator. "And we need independent adjudication and enhanced accountability of this practice."

Sapers' call is supported by a coroner's jury verdict Dec. 19, 2013. It found that the death of Ashley Smith, a young woman with serious mental health issues, who was in solitary confinement in a federal prison, was homicide. Among its 104 recommendations was the demand that "decision-making with respect to the clinical management and interventions of inmates with mental health issues [be] made by clinicians in consultation with the inmate, rather than by security management and staff."

The jury also demanded that a mental health professional visit all inmates in segregation or seclusion daily, in addition to meeting with individual inmates upon their request. The daily visit would focus on "assessing the inmate's tolerance to segregation."

The government has yet to respond to the jury's recommendations, Sapers notes. This is not the first call for an independent review of solitary confinement cases.

In 2012, the United Nations Human Rights Committee Against Torture stated that Canada should "limit the use of solitary confinement [to] a measure of last resort for as short a time as possible under strict supervision and with a possibility of judicial review."

Reviews of solitary confinement should be conducted in good faith by an independent body, agrees Juan Mendez, the UN's special rapporteur on torture and other cruel, inhuman or degrading treatment or punishment.

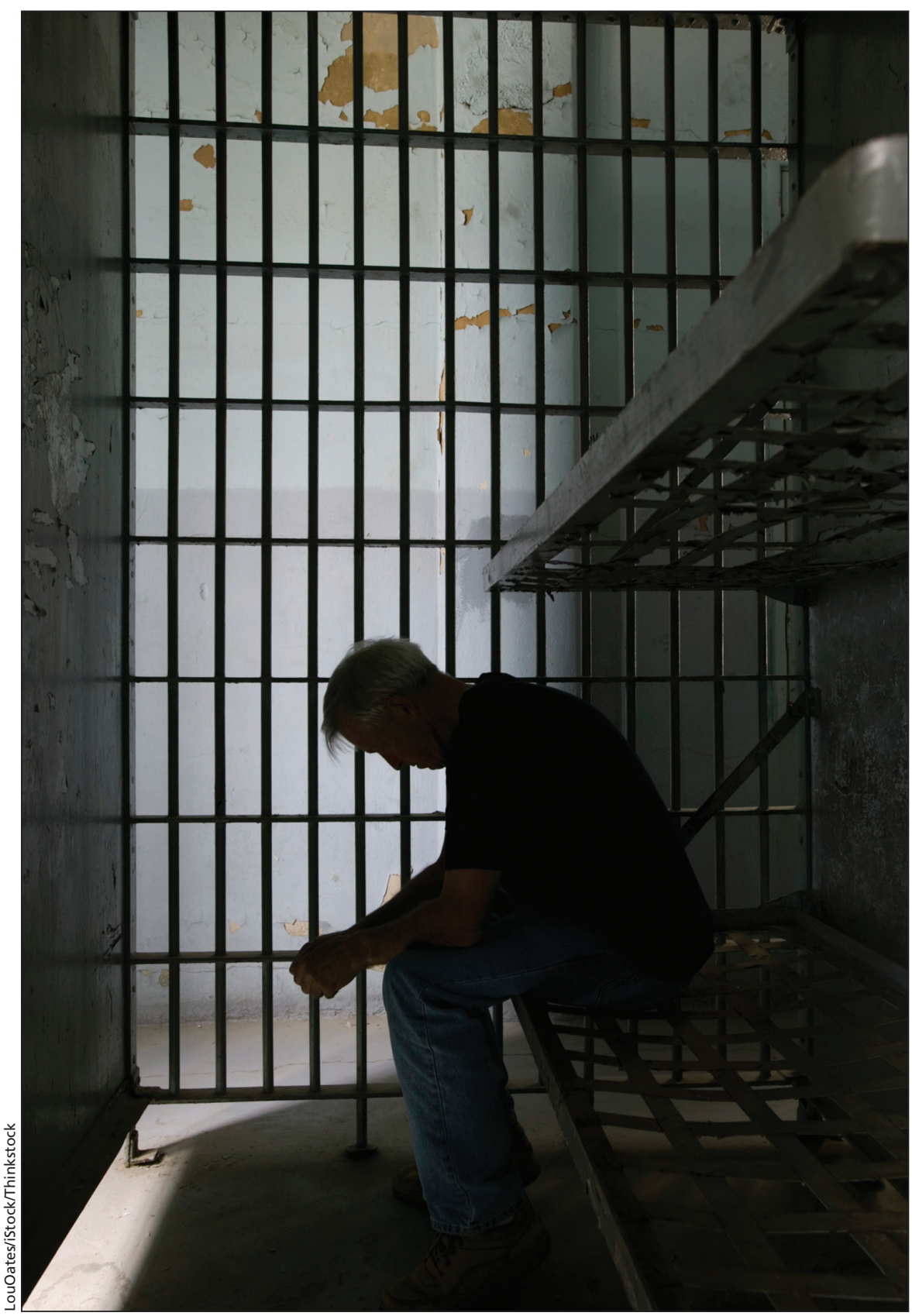

A UN human rights group is among those urging Canada to adopt a more humane approach to solitary confinement.

Since 2002, Canada has refused to sign the UN's Optional Protocol to the Convention against Torture and other Cruel, Inhuman or Degrading Treatment or Punishment that would lead to independent review of the use of solitary confinement, says Noa Mendelsohn
Aviv, a lawyer with the Canadian Civil Liberties Association. "Canada should ratify the [protocol] and establish a system of unannounced and unrestricted inspection visits to all places where persons are deprived of their liberty by independent international and national 
monitoring bodies," Mendelsohn Aviv says. "The government has been silent on this for more than a decade. Meanwhile, the problems have intensified."

Signing the protocol would bring Canada in line with 75 other countries including those in the UK, where the use of solitary confinement is monitored by external review committees in each prison and by a national committee, says Andrew Coyle, founding director of the International Centre for Prison Studies at the University of Essex. "We can't understand Canada's refusal to sign the protocol. Canada needs to adopt a far more sophisticated approach."

Kim Pate, executive director of the Canadian Association of Elizabeth Fry Societies, says Ashley Smith's case is not unique and the lessons from it have not been learned: a coroner's jury in Saskatchewan will soon review a similar case involving an Aboriginal woman named Kinew James who died in federal prison in 2013.

The Correctional Service of Canada (CSC) declined to be interviewed by
CMAJ. "CSC uses administrative segregation as a last resort for the shortest period of time necessary to manage the serious risk posed by an inmate's association with other inmates," CSC spokeswoman Melissa Hart stated in an email. "CSC is working on a comprehensive review of current research and operational practices of segregation."

Federal prisons are only part of the problem, says Jennifer Metcalfe, executive director of the Abbotsford, BCbased West Coast Prison Justice Society. She says they have clients who have spent months, even years, in "almost continual isolation within BC Corrections facilities." Many have pre-existing mental health problems; among those who don't, they "notice a deterioration of the mental health ... in segregation."

In 2010, the BC Supreme Court found that BC Corrections had "violated procedural fairness and natural justice" in denying an inmate a hearing and opportunity to respond during internal reviews "based on no information or information that was not assessed."
"If the Canadian public fully appreciated what is happening with solitary confinement in Canadian prisons, they'd be shocked," says Raji Mangat, a lawyer with the BC Civil Liberties Association who argued that CSC's treatment of Bobby Lee Worm, a 26-year-old Aboriginal woman from Saskatchewan who was held in solitary confinement for more than three and a half years while in federal prison, was illegal and inhumane.

Worm was a first-time offender and only 19 years old when she entered prison. Under the existing CSC management program during her years in solitary confinement, she spent up to 23 hours a day in a 10-by-8-foot cell.

Prison officials released Worm from the program two days after the BC Civil Liberties Association filed her lawsuit. - Paul Webster, Toronto, Ont.

See also editorial at www.cmaj.callookup〉 doi\10.1503\cmaj.141419

CMAJ 2015. DOI:10.1503/cmaj.109-4943 